\title{
Potential Indication of Propolis in Treatment of Oral Infection for Denture Wearers
}

\author{
Ibrahim H. Al-Fahdawi* \\ Department of Prosthodontics, College of Dentistry, Anbar University
}

Received: July 06, 2015; Accepted: October 09, 2015; Published: November 06, 2015

*Corresponding author: Ibrahim H. Al-Fahdawi, Assistant Professor, Department of Prosthodontics, College of Dentistry, Anbar University, Tel: 009647830808184; E-mail: ibrahimhm7@yahoo.com

\begin{abstract}
Propolis (bee glue ) is a sticky dark-coloured material that honey bees obtained from living natural plants that the bees mixed it with wax and applied it in their construction, building and adaptation of the nests specially to repair cracks and defects in the bee hive. It has been used in folk medicine since ancient times, and is now known to be natural medicine with, antibacterial, antifungal, antitumor, antioxiditive, mmunomodulatory properties. These therapeutic properties of propolis have been motivating isolation researches, identification of chemical compounds, and the possible relationship of these with its biological activity. It has been used in dentistry for surgical wound healing, root canal treatment, pulp capping and tooth hypersensitivity. Propolis has a promising role in future medicine. This article reviews the clinical application of propolis as a natural medicine in dentistry. Furthermore; systemic and clinical applications of these drugs may have some adverse effects like liver toxicity, drug interactions etc. Using propolis as antifungal by local application shown that it reduces the incidence of dry socket and denture stomatitis that associated with the Candida. The propolis past was used in the following manner. It can be applied to the fitting surface of denture, twice a day for 2 weeks. The propolis putty can also applied to dry socket cases after complete debridement and irrigation of it. The results confirmed that the signs and symptoms including pain, redness area and inflammation related stomatitis were removed gradually after 2-14 days that the denture stomatitis is healing by using a propolis paste. Propolis putty treat the fungal inflammation of dry socket that gradual decreases of the pain and inflammation. After the treatment, all patients with denture stomatitis were subjected to evaluation and examination of the mucosa, socket and Candidal quantitative culture and confirmation of diagnosis by three method: Germ tune, Gram Stain. and ChromAgar media.
\end{abstract}

Keywords: Propolis, oral infection, denture stomatitis, dry socket

\section{Introduction}

Propolis is a mixture of different amounts of beeswax and resins that obtained by the honeybee from different natural plants, especially from flowers and leaf buds. It would be considered in the process of gathering, shaping and remodeling the resins that are collected and added to saliva and other fluid secretions of the bees in addition with wax[1, 2]. They applications are important because they have a privilege of the antibacterial and antifungal effects of propolis in keeping the colony against diseases[3, 4 ,
5]. Bee Propolis is considered to have a higher healing features in addition to its capability to increase the new cell growth[6, 7]. The word propolis came from Greek: «pro»= in front, «polis»= city. The meaning „, in front of the city,, suits well the protecting role of propolis for the bee colony. The Greek world propolis also known as glue and describes the role of propolis to cement and seals the openings and cracks of the bee hive[8].

Although antibacterial activity is more relevant than the antifungal properties of propolis, many studies have reported the susceptibility of clinically important yeasts belonging to Candida genera $[9,10,11]$ such as Candida albicans $[12,13]$, as well as the sensitivity of some filamentous fungi mainly dermatophites[14]. Longhini and co-workers, ${ }^{[15]}$ stated that propolis has antifungal features in dermatophytes even in small concentrations, having reduced toxicity and in turn it can be applied topically. Differences in antifungal activity of propolis extracts can again be related to the differences in chemical structure and concentration of propolis elements and composition. As for antibiotics, a synergistic effect with conventional antimycotic drugs was observed[16].

Propolis is lipophilic in nature, rigid, fragile and brittle material when cold; but when temperature rises, it becomes soft, pasty , gummy and adhesive properity and be sticky. It possesses a characteristic and pleasant aromatic smell and varies in color from yellow green, to red and to dark brown depending on its source and age. The color of propolis varied from yellow to be more darker brown according to the origin of the resins[17]. Propolis is its prohibition effect on specific and particular prostaglandins that achieved by blocking the enzymes that form specific prostaglandins which can be much more beneficial to the mouth and throat. For instance, a leading reason for dental problems is the gum and tissue erosion which line the tooth sockets. Infectious bleeding and Inflammation may lead to tooth loss as well as a weakening of the bone structure. Nevertheless, propolis, can inhibits production of the prostaglandins that resulting in the bleeding, inflammation as well as eventual decomposition. At the same time, propolis actually promots other specific enzymes that improved strengthen the blood vessels walls that distributed in the gums leading to a twofold effect on the mouth[18,19]. 
Propolis is a complex content that result from mixing of natural plant derived and bee released elements and compounds. The proportion of the various materials found in the propolis that related to its place and time of collection but, in general, raw propolis is estimated to have a composition of around $50 \%$ resins, $30 \%$ waxes, $10 \%$ essential oils, $5 \%$ pollen and $5 \%$ of various organic Compounds $[20,12]$. The chemical structure and composition of propolis is complex; flavonoid and (hydroxyl) cinnamic acid derivatives are found to be the primary biologically essential composition in propolis extract [1]. Other materials and elements include flavonoids, amino acids, B vitamins, and most importantly, antibiotic substances [21, 22]. Furthermore, depending on its geographical origin, its composition is highly variable. More than 300 constituents were identified in different samples, and new ones are still being recognized during chemical characterization of new types of propolis $[17,23,24]$. The most favorite solvents can be applied for commercial extraction are ethanol (ethyl alcohol) ether, glycol and water. For chemical analysis, a different solvents can be applied in order to extract the assorted fractions. Many of the bactericidal components are soluble in water or alcohol[25].

\section{Materials and methods}

Propolis was collected from honeycombs, dried and subjected to exhaustive maceration, filtered using aqueous ethanol, and concentrated using a rotary evaporator. The residue was separated, which were subjected to silica gel chromatography[26]. Propolis is a natural black-green putty derived from honeydew was produced by bees, used to close gaps occur in honeycomb and act as antifungal to prevent any contamination for it. The propolis either putty used for dry socket or paste (putty dissolved in alcohol to produce creamy like mixture) used for denture stomatitis. The propoils paste was used in the following manner. It can be put to the inner surface of denture, twice times per a day for two successive weeks. Before cream was spread, the inner surface of the dental prosthesis was carefully and thoroughly cleaned with toothbrush, soap and water to remove any depress from the preceding application. After complete removal of inflammatory tissues, dry socket was filled by propolis putty. Propolis putty treat the fungal inflammation of dry socket that gradual decreases of the pain and Inflammation. The putty dissolved inside socket and start action as antifungal after some hours. After the treatment, all patients were followed up by evaluation and examination of the dental socket as well as the palatal mucosa and Candidal quantitative culture from the palatal mucosa, denture-fitting surface and diagnosed by three methods:

1-Germ tube[27, 28, 29]

2-Gram Stain[30, 31]

3-ChromAgar media[29]

\section{Result and Discussion}

In general, propolis is much more safe, non-toxic substance and have no irritation when used as supplements or applied topically to skin. However, like other honeybee products, allergic or adverse reaction may be due to this substance as an occupational effect. It is confirmed that that a substance called caffeic acids to be one of the leading causes of propolis allergies. Denture stomatitis can be represents as a chronic illness in denture bearing dental patients notably under maxillary prosthesis. Although, there are large number of antifungal agents, treatment failure is noticed mostly. The results stated that all signs and symptoms of redness, bleeding, pain, tender area and inflammation related stomatitis were removed gradually within 2-14 days when no inflammation was evident in the propolis treated. Since the reason of the denture stomatitis is varied, several treatment optional procedures are to be considered, like correction of ill-fitting dentures, plaque control and topical or systemic antifungal therapy. Rough areas on the tissue surface of the denture are needed to be smoothened in dental labrotary. The result is in agreement with the following: Nystatin tablets 500,000 units were allowed to dissolve in the mouth three times a day for 14 days. Bergendal and Isacsson reported similar results by treating denture stomatitis with nystatin powder, placed on the fitting surface of the denture, three times a day for 14 days [32]. Nystatin is formulated for oral use as suspension or pastille. A miconazole varnish or gel can be topically administrated in denture related stomatitis. A once daily application of the miconazole varnish or a twice-daily application of the miconazole gel for two weeks is sufficient [33].

Martins et al. (2002), find the propolis extract used in this study inhibited the in vitro growth of C. albicans. Santos et al. (2008) and Parolia et al.,(2010) evaluated the clinical efficacy of a propolis gel formulation in patients diagnosed with denture stomatitis. Propolis had been applied to avoid the clinical application of systemic antifungal agents in nystatin resistant cases. Side effects such as itching and complications such as allergic contact dermatitis had been reported. However, propolis paste used by the patient easily without side effect as allergy or itching and easy removed from denture surface. Denture stomatitis is an inflammatory process that is appear in many dental patients people as result of candida related by the use of unhygienic denture or trauma. Though Candida albicans is a component of normal oral micro flora, many local and systemic factors can alter them to be a pathogen. Management of Denture stomatitis related to accurate history taking and proper diagnosis, identification and elimination of predisposing factors and often use of antifungal agents. Topical application of nystatin, amphoteresin, miconazole etc: are effective in many cases. Because the biofilm formation in candidiasis is highly resistant to antifungal agents, systemic ketoconazole, fluconazole, or itraconazole can be used. Furthermore, there were some interactions of drugs to overcome the clinical application of systemic antifungal agents; propolis cream was tried in candida related denture stomatitis. Propolis in a paste form can be used twice times per a day on the fitting inner surface of the denture base for 14 days has been proved to be much more effective. Propolis putty treat the fungal inflammation of dry socket that gradual reduction of the clinical signs and symptoms of pain and inflammation. The putty dissolved inside socket and start action as antifungal after some hours. 


\section{References}

1. Kosenco SV and Kosorich Tiu .The Treatment of periodontitis with research).Stomatologia-MOSK 1990;69:27-29.

2. Mathivanan V, et al, A review on Propolis - as Folk Medicine, Indian J. of Scie. Vol. 2 No. 3 Jan. 2013

3. CRANE, E . History of other products from bees The world history of beekeeping and honey hunting. Gerald Duckworth \& Co Ltd:London;1999:545-553.

4. Vijay D Wagh*and Rameshwar D Borkar. indian propolis: a potential natural antimicrobial and antifungal agent. International Journal of Pharmacy and Pharmaceutical Sciences, Vol 4, Issue 4, 2012

5. Almas K. Propolis as a natural remedy: An update. Saudi Dent J 2001; 13(1):45-9.

6. Seidel V, Peyfoon E, Watson DG, Fearnley J. Comparative study of the antibacterial activity of propolis from different geographical and climatic zones. Phytother. Res. 2008; 22(9):1256-1263. doi: 10.1002/ ptr.2480.

7. Velazquez C, Navarro M, Acosta A, Angulo A, Dominguez Z, Robles R,Robles-Zepeda R, Lugo E, Goycoolea FM, Velazquez EF, Astiazaran $\mathrm{H}$, Hernandez J Antibacterial and free radical scavenging activities of Sonoran propolis. J Appl. Microbiol. 2007; 103(5): 1747-1756.

8. Vijay D Waghand Rameshwar D Borkar, indian propolis: a potential natural antimicrobial and antifungal agent, International Journal of Pharmacy and Pharmaceutical Sciences ISSN- 0975-1491 Vol 4, Issue 4, 2012

9. Kujumgiev A, Tsvetkova I, Serkedjieva Y, Bankova V, Christov R, Popov S. Antibacterial, antifungal and antiviral activity of propolis from different geographic origins. Journal of Ethnopharmacology. 1999; 64(3):235-240.

10. Kartal M, Yıldız S, Kaya S, Kurucu S, Topcu G. Antimicrobial activity of propolis samples from two different regions of Anatolia. Journal of Ethnopharmacology. 2003; 86(1): 69-73.

11.Stepanović S., Antić N., Dakić I., Švabić-Vlahović M. In vitro antimicrobial activity of propolis and synergism between propolis and antimicrobial drugs. Microbiological Research. 2003. 158(4):353-357.

12. Hegazia AG, Abd El Hady FK, Abd Allah FA. Chemical Composition and Antimicrobial Activity of European Propolis. Z. Naturforsch. 2000; 55(1-2):70-75

13. Trusheva B, Popova M, Bankova V, Simova S, Marcucci MC, Miorin PL, da Rocha Pasin F, Tsvetkova I. Bioactive constituents of Brazilian red propolis. Evidence-based Complementary and Alternative Medicine. 2006; 3(2):249-254.

14. de Castro SL. Propolis: biological and pharmacological activities Therapeutic uses of this bee-product. Annual Review Biomedical Sciences. 2001; 3:49-83.

15. Longhini R, Raksa SM, Oliveira ACP, Svidzinski TIE, Franco SL Obtencao de extratos de propolis sob diferentes condicoese avaliacao de sua atividade antifungica. Brazilian Journal of Pharmacognosy. 2007; 17(3); dx.doi.org/10.1590/S0102-695X2007000300015.

16. Oliveira ACP, Shinobu CS, Longhini R, Franco SL, Svidzinzki TIE Antifungal activity of propolis extract against yeasts isolated from onychomycosis lesions. Memórias do Instituto Oswaldo Cruz. 2006; 101(5):493-497.

17.17. Bankova V, Castro SL \& Marcucci MC, Propolis: Recent advances in chemistry and plant origin, Apidologie 2000;31:3-15.
18.18. Koya-Miyata S, Arai N, Mizote A, Taniguchi Y, Ushio S, Iwaki K, Fukuda S. Propolis Prevents Diet-Induced hyperlipidemia and mitigates weight gain in Diet-Induced obesity in mice. Biol. Pharm. Bull. 2009;32(12):2022-2028.

19.19. Izuta H, Shimazawa M , Tsuruma K, Araki Y, Mishima S, Hara . Bee products prevent VEGF-induced angiogenesis in human umbilical vein endothelial cells. BMC Complementary and Alternative Medicine 2009, 9:45. 1-10. doi:10.1186/1472-6882-9-45.

20.20. Burdock GA, Review of the biological properties and toxicity of bee propolis, Food Chem Toxicol 1998;36(4):347-363.

21.21. Park YK, Alencar SM \& Aguiar CL, Botanical origin and chemica composition of Brazilian propolis, J Agric Food Chem 2002;50(9):25022506.

22.22. Almas K, Dahlan A, Mahmoud A. Propolis as a natural remedy: An update. Saudi Dental J. 2001;13: 45-49.

23.23. Alencar SM, Oldoni TLC, Castro ML, Cabral ISR, Costa-Neto CM, Cury JA, Rosalen PL \& Ikegakid M, Chemical composition and biological activity of a new type of Brazilian propolis: Red propolis, J Ethnopharmacol 2007;113(2):278-283.

24.24. Stefan Bogdanov, Propolis: Composition, Health, Medicine: A Review, Bee Product Science. 2012;15.

25.25. N.Kalavathy, Sridevi.J,P.Roshan Kumar,Sharmila.M.R,Jayanthi.N. Denture induced fibrous hyperplasia: A case report 258 Streamdent.2010; 1(3).

26.26. Sabir A. The identification of flavonoid groups in trigona propolis collected from Bulukumba regency south Sulawesi used on direct pulp capping treatment. Majalah Kedokteran Gigi(Dental Journal) (In Indonesia),2003;59-63.

27.27. Evans E. G. and Richarardson, (1989).Medical Mycology a practical a proach. IRL Press ,U.K.

28.28. Ron J. Doyle. (1999). Biofilms, Methoda in Enzymology, 310: 644656.

29.29. James DB. Biofilms II: Process Analysis and Applications. New York, USA: Wiley-liss; 2000.

30.30. Philip D Marsh and Michael V. Martin. (2009). Oral Microbiology.,Churchili livingstone Elsever., London, U. K.

31.31. Odds F.C. (1979). Candida and Candidiosis .mLeicester University, U.K.

32.32. George. A. Zarb Charles L. (2004). Bolender; Sequelae caused by wearing complete dentures, 12 th Edn :Elsevier, pp. 34-50.

33.33. Lucio Milillo, Lo Muzio L, Carlino P, Serpico R, Coccia E, Scully C.Candida related Denture Stomititis A pilot study of the efficacy of an amorolfine antifungal varnish, Int. J. Prosthodont . 2005;18(1): 55-59.

34. 34. Martins RS, Péreira ES Jr, Lima SM, Senna MI, Mesquita RA, Santos VR Effect of commercial ethanol propolis extract on the in vitro growth of Candida albicans collected from HIV-seropositive and HIVseronegative Brazilian patients with oral candidiasis. J. Oral Sci. 2002; 44(1): 41-48.

35.35. Santos VR, Gomes RT, de Mesquita RA, de Moura MD, França EC, de Aguiar EG, Naves MD, Abreu JA, Abreu SR. Efficacy of Brazilian propolis gel for the management of denture stomatitis: a pilot study. Phytother. Res.2008; 22(11): 1544-1547. doi: 10.1002/ptr.2541.

36. 36. Abhishek Parolia, Manuel S. Thomas, M. Kundabala and Mandakini Mohan. Propolis and its potential uses in oral health. International Journal of Medicine and Medical Sciences Vol. 2(7) pp. 2010; 210-215. 